\title{
Associations between tamoxifen, estrogens, and FSH serum levels during steady state tamoxifen treatment of postmenopausal women with breast cancer
}

\author{
Jennifer Gjerde1,2, Jürgen Geisler3,4,5, Steinar Lundgren6,7, Dagfinn Ekse3, Jan Erik Varhaug 8,9, Gunnar Mellgren 1,2, \\ Vidar M Steen 10,11 and Ernst A Lien ${ }^{* 1,2}$
}

\begin{abstract}
Background: The cytochrome P450 (CYP) enzymes 2C19, 2D6, and 3A5 are responsible for converting the selective estrogen receptor modulator (SERM), tamoxifen to its active metabolites 4-hydroxy-tamoxifen (4OHtam) and 4hydroxy-N-demethyltamoxifen (4OHNDtam, endoxifen). Inter-individual variations of the activity of these enzymes due to polymorphisms may be predictors of outcome of breast cancer patients during tamoxifen treatment. Since tamoxifen and estrogens are both partly metabolized by these enzymes we hypothesize that a correlation between serum tamoxifen and estrogen levels exists, which in turn may interact with tamoxifen on treatment outcome. Here we examined relationships between the serum levels of tamoxifen, estrogens, follicle-stimulating hormone (FSH), and also determined the genotypes of CYP2C19, 2D6, 3A5, and SULT1A1 in 90 postmenopausal breast cancer patients.

Methods: Tamoxifen and its metabolites were measured by liquid chromatography-tandem mass spectrometry. Estrogen and FSH levels were determined using a sensitive radio- and chemiluminescent immunoassay, respectively.

Results: We observed significant correlations between the serum concentrations of tamoxifen, $\mathrm{N}$ dedimethyltamoxifen, and tamoxifen- $N$-oxide and estrogens $(p<0.05)$. The genotype predicted CYP2C19 activity influenced the levels of both tamoxifen metabolites and $E 1$.

Conclusions: We have shown an association between tamoxifen and its metabolites and estrogen serum levels. An impact of CYP2C19 predicted activity on tamoxifen, as well as estrogen kinetics may partly explain the observed association between tamoxifen and its metabolites and estrogen serum levels. Since the role of estrogen levels during tamoxifen therapy is still a matter of debate further prospective studies to examine the effect of tamoxifen and estrogen kinetics on treatment outcome are warranted.
\end{abstract}

\section{Background}

Estrogens play a key role in breast cancer development. The selective estrogen receptor modulator (SERM) tamoxifen has been used in breast cancer treatment and prevention. It may act as a full estrogen agonist, partial agonist or antagonist depending on the dose, species, sex or target organ [1]. Tamoxifen is regarded as a pro-drug since two of its metabolites, 4-hydroxytamoxifen (4OHtam) and 4-hydroxy- $\mathrm{N}$-demethyltamoxifen

\footnotetext{
* Correspondence: Ernst.Lien@med.uib.no

1 Hormone Laboratory, Haukeland University Hospital, Bergen, N-5021, Norway Full list of author information is available at the end of the article
}

(4OHNDtam, endoxifen), both have estrogen receptor affinity markedly exceeding that of tamoxifen itself $[2,3]$. The 4OHNDtam is considered the main active metabolite of tamoxifen, since it has 100-fold higher affinity for the estrogen receptor (ER) than tamoxifen and is 10-fold higher in serum levels than 4OHtam [4-7]. These potent metabolites are converted from tamoxifen through the cytochrome P450 (CYP) enzymes 2C19, 2D6, and 3A5. They are conjugated and deactivated through sulfotransferase (SULT) 1A1 [8,9] and UDP-glucuronyltransferases. The inter-individual variations of the activity of these enzymes due to genetic polymorphisms could therefore 
be predictors of outcome during tamoxifen treatment considering their influence on the concentration of the active metabolites 4OHNDtam and 4OHtam [7]. However, the results from clinical studies are partly contradictory [10-20]. The conflicting results may be explained by differences in study designs, including size, different genetic models for the assessment of phenotypes, or dosing regimens.

Tumors that initially respond to tamoxifen treatment develop resistance over time [21]. Several mechanisms resulting in tamoxifen resistance have been suggested. Among others the findings of Berstein et al that longterm exposure to tamoxifen induces hypersensitivity to $17 \beta$-estradiol (E2) suggests that E2 levels may be of importance when resistance developes [22].

Hormonal changes involving the elevation of serum concentrations of follicle-stimulating hormone (FSH) and cessation of E2 levels during and after the menopause are related to the frequency of hot flashes $[23,24]$, which in turn have been suggested as a predictor of tamoxifen efficacy $[25,26]$. Patients carrying functional CYP2D6 alleles been reported to have a higher incidence of hot flashes, higher levels of the active metabolites of tamoxifen, and better outcome during tamoxifen treatment $[7,25,26]$.

Tamoxifen and estrogens are both partly metabolized by the enzymes CYP2C19, 2D6, 3A5, and SULT1A1 (Figure 1) [27]. Therefore, we hypothesized that these genotypes that are proposed predictors for response to tamoxifen influence estrogen metabolism and that correlations between serum tamoxifen and estrogen levels exist. Here, we examined relationships between the serum levels of tamoxifen, estrogens, follicle-stimulating hormone (FSH), and sex hormone-binding globulin (SHBG) in postmenopausal breast cancer patients. We also determined the genotypes of CYP2C19, 2D6, 3A5, and SULT1A1. We observed an association between tamoxifen and its metabolites and estrogen serum levels. The CYP2C19 predicted activity influenced both tamoxifen and estrogen kinetics.

\section{Methods}

\section{Patients}

From a study on tamoxifen metabolism in pre- and postmenopausal women adjuvantly treated with tamoxifen 20 mg daily, we included exclusively postmenopausal women in order to examine patients with stable estrogen and FSH levels [7]. Postmenopausal status was defined as FSH levels $>20 \mathrm{IU} / \mathrm{L}$ and E2 levels $<70 \mathrm{pmol} / \mathrm{L}$, using the automated analyzer Immulite 2000 (Diagnostic Products Corporation, Los Angeles, CA). All patients with estrogen receptor and/or progesterone receptor-positive tumors gave their written informed consent to participate in the investigation. The protocol was approved by the National Committee for Medical and Health Research
Ethics (NEM). Due to the long half-life of tamoxifen and to ensure that these patients had reached steady-state drug levels, only patients treated for at least 80 days were included in the study. All patients were informed to avoid tamoxifen ingestion on the morning of blood sampling. Whole blood and serum samples were immediately frozen and kept at $-80^{\circ} \mathrm{C}$ until analysis.

\section{Determination of tamoxifen and its metabolites concentrations}

Tamoxifen citrate and 4OHtam were purchased from Sigma-Aldrich (Steinheim, Germany), the internal standard deuterated5-tamoxifen $\left(\mathrm{D}_{5} \mathrm{tam}\right)$ and tamoxifen- $\mathrm{N}$ oxide (TamNox) from Beta Chem Inc. Life Science, Research \& Development (Kansas City, US), 4OHNDtam from Sintef Materials and Chemistry (Oslo, Norway). $N$ demethyltamoxifen (NDtam) and $\mathrm{N}$-dedimethyltamoxifen (NDDtam) were gifts from Imperial Chemical Industries, PLC Pharmaceutical divisions (Macclesfield, UK). A high-pressure liquid chromatography-tandem mass spectrometry system was used for the determination of tamoxifen, 4OHtam, 4OHNDtam, NDtam, NDDtam and tamNox in serum $[7,28]$.

\section{Determination of hormones and SHBG concentrations}

FSH and SHBG levels were measured using the Immulite 2000 (Diagnostic Products Corporation, Los Angeles, CA). Serum levels of E2, estrone (E1), and estrone sulfate (E1S) were determined using a novel and highly sensitive radioimmunoassay where the detection limit for E2, E1, and E1S were $0.67 \mathrm{pmol} / \mathrm{L}, 1.14 \mathrm{pmol} / \mathrm{L}$ and $0.55 \mathrm{pmol} / \mathrm{L}$, respectively [29].

\section{CYP2C19 genotype determination}

Genomic DNA was extracted and purified from the whole blood samples using the QIAmpR DNA Blood Mini Kit as described in the manufacturer's (QIAmpR DNA Blood Mini Kit) handbook (Qiagen, Hilden, Germany).

CYP2C19 *2 (rs 4244285) and *3 were detected using the LightMix assay kit (TiBMolBiol, Berlin, Germany). CYP2C19"17 (806C_T and 3402C_T) were determined by DNA sequencing and hybridization probe-based realtime PCR assay (Roche). For CYP2C19*17 (806C_T), we used the primer 5'-AGTGGTTCTATTTAATGTGAAGCCT -3' (forward) and 5'-GGTCTCCCTTTCCCATTTG -3' (reverse). The PCR product was bidirectionally sequenced using Big Dye Terminator version 3.1 Cycle Sequencing kit according to the manufacturer's recommendations on an ABI Prism 3700 DNA Analyzer (Applied Biosystems). The CYP2C19*17 (3402C_T) variant allele was determined by a hybridization probe-based real-time PCR assay (Roche), using the primer 5'-ATATCTGATAAATGATGGCTATCC-3' (for- 
Figure $1 \mathrm{~A}$

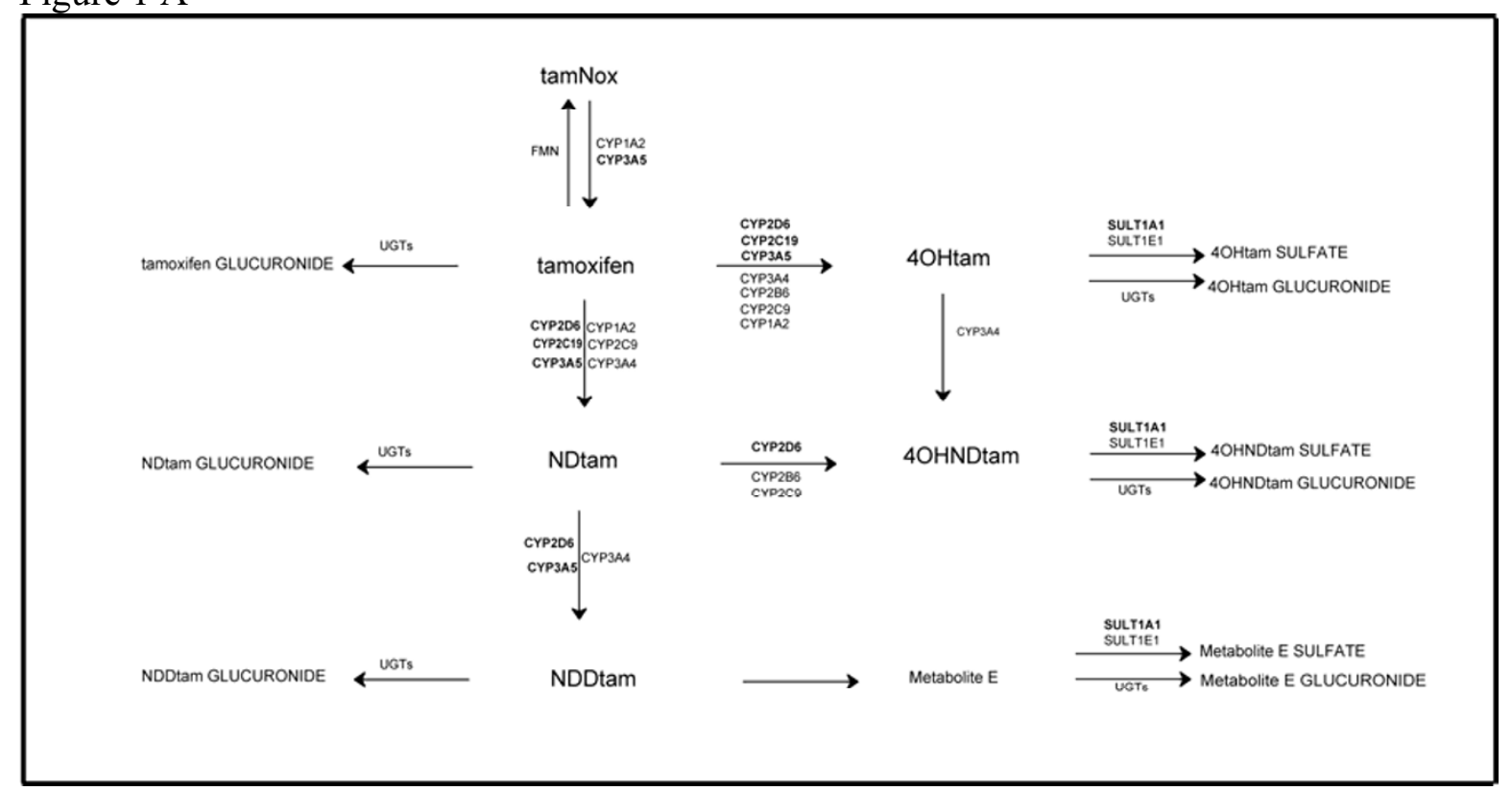

Figure 1 B

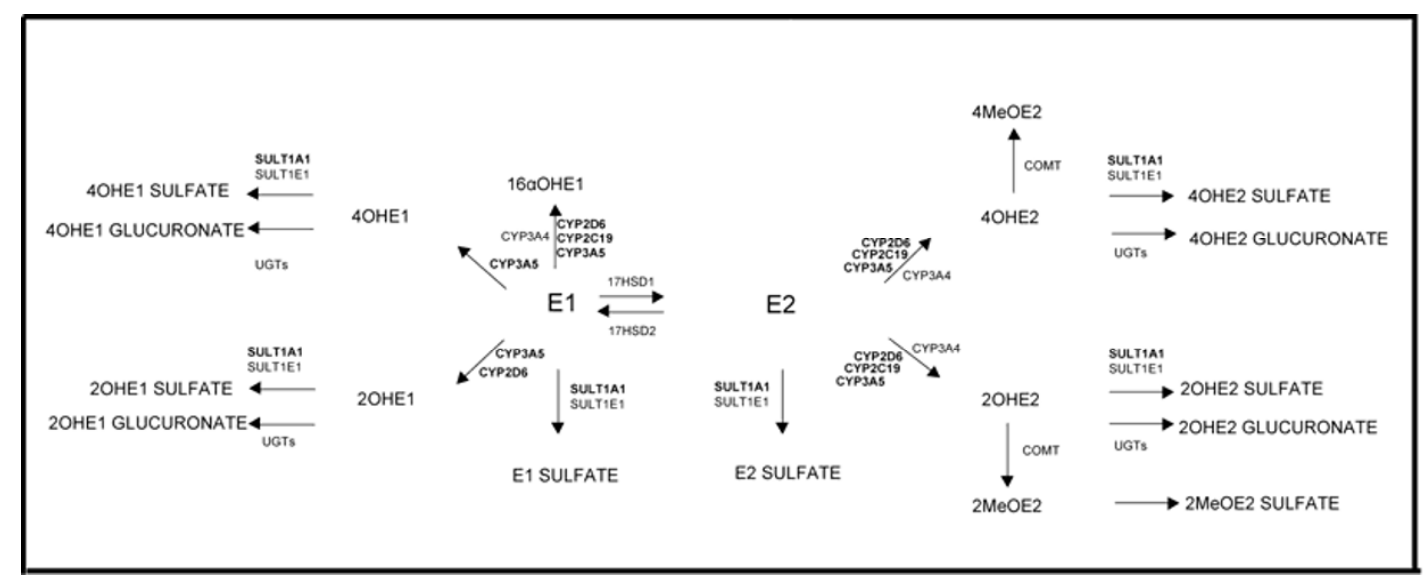

Figure 1 Schematic representation of (A) tamoxifen and (B) estradiol metabolism and the enzymes involved. 4OHtam, 4-hydroxytamoxifen; 4OHNDtam, 4-hydroxy- $\mathrm{N}$-demethyltamoxifen; NDtam, N-dedimethyltamoxifen; NDDtam, N-dedimethyltamoxifen; tamNox, tamoxifen- $\mathrm{N}$-oxide; CYP, cytochrome P450; SULT, sulfotransferase; UGT, Uridine 5'-diphospho-glucuronosyltransferase; E2, estradiol; E1, estrone; E1S, estrone sulphate; 4OHE2, 4-hydroxyE2; 2OHE2, 2-hydroxyE2; 4MeOE2, 4-methoxyE2; 2MeOE2, 2-methoxyE2; 4OHE1, 4-hydroxyE1; 2OHE1, 2-hydroxyE1; 4MeOE1, 4-methoxyE1; 2MeOE1, 2-methoxyE1; 16aOHE1, 16a-hydroxyE1; Catechol-O-methyl transferase, COMT. Bolded texts indicate tamoxifen and estrogen metabolizing enzymes investigated.

ward) and 5'-CTGCAAGCTAAAACCCC-3' (reverse). The detection probe used was 5'-LC Red640-GACCCGTTGCCCATTTTTTTAATCAA--PH and the anchor probe was 5'-TGTCTTCTTGGTGAGATGTCTGTTC--FL (TIB MolBiol, Berlin, Germany).

\section{CYPD6 genotype determination}

Genomic leukocyte DNA was extracted from EDTA-anticoagulated whole blood using the QIAamp DNA Blood Mini Kit (Qiagen, Hilden, Germany). The CYP2D6 genotypes were tested previously and subdivided into four 
groups and ranked according to their predicted increasing enzymatic activity: poor metaboliser (PM) [subjects with any combination of two nonfunctional variant type (Vt) alleles *3, *4, 5 and *6], intermediate metabolizer (IM) wild type/variant type CYP2D6, wild type/wild (Wt/ Wt) type CYP2D6, and ultra rapid metabolizer (UM) [heterozygous Vt allele *2 $\times 2$ ] [7].

\section{CYP3A5 genotype determination}

The most common CYP3A5 variant (*3) was tested to identify patients with low CYP3A5 protein expression. This allele is present in approximately 20\% Asian, 50\% African-American, and $90 \%$ Caucasian populations. The CYP3A $5 * 3$ variant allele was determined by a hybridization probe-based real-time PCR assay (Roche, Germany), using the primer 5'-TTTGCCTCTTTGTACTTCTTCATC-3' (forward) and 5'-TAGTTGTACGACACACAGCAACC-3' (reverse). The detection probe was 5'-LC Red640-GTTTGGACCACATTACCCTTCATC--PH and the anchor probe was 5'-CTTTTGTCTTTCAATAT CTCTTCCC--FL (TIB MolBiol, Berlin, Germany).

\section{SULT1A1 genotype determination}

We screened for the SULT1A1*2 variant allele with a hybridization probe-based real-time PCR assay. To verify these results, a PCR-based restriction fragment length polymorphism assay and bi-directional sequencing were used as previously published [7]. The SULT1A1 copy number was estimated by calculating the height and area ratio of the $210 \mathrm{bp}$ amplicon of SULT1A1 to the reference 205 bp amplicon of SULT1A2 as described by Hebbring et al [30].

\section{Statistical analyses}

CYP2C19 was sub-divided into five groups and ranked according to their predicted increasing enzymatic activity: " $2 / 22$ were subjects homozygous for the variant allele CYP2C19*2, "1/*2, were subjects heterozygous for the variant allele CYP2C19*2, homozygous wild type allele CYP2C19"1, CYP2C19"2/"17, "1/"17 were subjects heterozygous for the CYP2C19*17 variant allele, and "17/ "17 were subjects homozygous for the CYP2C19"17 variant allele.

CYP2D6 was sub-divided into four groups and ranked according to their predicted increasing enzymatic activity: PM, IM, Wt/Wt, and UM. CYP3A5 was divided into CYP3A5*3/*3 and CYP3A5*1/*3 groups. SULT1A1 genotype and gene dosage were also sub-divided into groups and ranked according to their predicted increasing enzymatic activity: ${ }^{*} 2 /{ }^{*} 2,{ }^{*} 1 / * 2$ and $" 1 / * 1$ and increasing copy number, respectively. Statistical analyses were conducted using SPSS statistical software (version 12; SPSS, USA). All statistical tests were two-sided.

The serum levels of tamoxifen and its metabolites, estrogens, FSH, and SHBG are given as median values and inter-quartiles ranges. The Spearman rank correlation coefficient was calculated in order to assess the association between two variables. Bonferroni correction was applied to take account of multiple comparisons. All $\mathrm{P}$ values were two sided. A multivariate logistic regression model was applied. The serum levels of tamoxifen and its metabolites (tamoxifen, 4OHtam, 4OHNDtam, NDtam, NDDtam, and TamNox), metabolic ratios (4OHtam/tam, tamNox/tam, NDtam/tamNox, and 4OHNDtam/ NDtam) and estrogens (E2, E1, and E1S) were dependent variables and all genotypes (CYP2C19, CYP2D6, CYP3A5, SULT1A1, and SULT1A1 copy number), FSH, and SHBG were explicative variables. All tests were conducted at the $\mathrm{P}=0.05$ level of significance.

\section{Results}

Patients

Ninety patients (median age 62 years) were enrolled in this study. The median duration of tamoxifen treatment of patients included was 571 days (Table 1). The median [range] serum concentrations of E2 and FSH were 9.4 [1.3-54.7] $\mathrm{pmol} / \mathrm{L}$ and 38.2 [20.3-108.0] IU/L, respectively, were consistent with post-menopausal values (Table 1). The serum level of SHBG was 81 [27-173]. Notably, we detected tamoxifen and its metabolites in all serum samples [range 31-247 $\mathrm{ng} / \mathrm{ml}$ for tamoxifen] indicating good compliance for the patients included (Table $1)$.

Table 1: Age, duration of treatment, and biochemical and pharmacological parameters $(n=90)$

\begin{tabular}{llll}
\hline Variables & \multicolumn{3}{l}{ Median [Range] } \\
\hline Age & 62 & {$[48-85]$} & Year \\
Tamoxifen duration & 571 & {$[84-4380]$} & Days \\
E21 & 9.4 & {$[1.3-54.7]$} & $\mathrm{pmol} / \mathrm{L}$ \\
E1 & 98.6 & {$[29.3-355.6]$} & $\mathrm{pmol} / \mathrm{L}$ \\
E1S & 582 & {$[30-2923]$} & $\mathrm{pmol} / \mathrm{L}$ \\
FSH & 38.2 & {$[20.3-108.0]$} & $\mathrm{IU} / \mathrm{L}$ \\
SHBG & 81 & {$[27-173]$} & $\mathrm{nmol} / \mathrm{L}$ \\
Tam & 96 & {$[31-247]$} & $\mathrm{ng} / \mathrm{ml}$ \\
$4 O H t a m$ & 5.8 & {$[2.7-17.2]$} & $\mathrm{ng} / \mathrm{ml}$ \\
$4 O H N D t a m$ & 50.7 & {$[25.1-184.8]$} & $\mathrm{ng} / \mathrm{ml}$ \\
NDtam & 230 & {$[116-596]$} & $\mathrm{ng} / \mathrm{ml}$ \\
NDDtam & 39.8 & {$[15.7-93.4]$} & $\mathrm{ng} / \mathrm{ml}$ \\
tamNox & 9.6 & {$[3.5-37.9]$} & $\mathrm{ng} / \mathrm{ml}$ \\
\hline
\end{tabular}

${ }^{1} E 2$, estradiol; E1, estrone; $E 1 S$, estrone sulfate; $F S H$, follicle stimulating hormone; SHBG, sex hormone binding globulin; tam, tamoxifen; 4OHtam, 4-hydroxytamoxifen; 4OHNDtam, 4hydroxy-N-demethyltamoxifen; NDtam, N-demethyltamoxifen; NDDtam, N-dedimethyltamoxifen; tamNox, tamoxifen-N-oxide. 


\section{Frequencies and genotypes distribution}

From a total of 90 subjects, the distribution of CYP2C19 "2/"2, " $1 /{ }^{*} 2$, " $1 /{ }^{*} 1$, heterozygous $* 17\left(* 2 / * 17\right.$ and $\left." 1 /{ }^{*} 17\right)$ and $" 17 / * 17$ were $4.4 \%, 16.7 \%, 38.9 \%, 36.7 \%$ and $3.3 \%$, respectively. The CYP2C19*3 allele was not detected. The two single-nucleotide polymorphisms characterizing the CYP2C19*17 allele (806C_T and 3402C _ T) were found in complete linkage disequilibrium in our study population (Table 2).

The CYP2D6 PM-, IM, Wt/Wt, and UM-genotypes distribution of the patients were $6.7 \%, 35.5 \%, 56.7 \%$, and
$1.1 \%$ respectively (Table 2 ). $84.4 \%$ of the patients carried CYP3A5*3/*3 and $15.6 \%$ were CYP3A5*1/*3. The distribution of SULT1A1*1/*1, SULT1A1*1/*2, and SULT1A1 $2 / * 2$ were $48.9 \%, 35.5 \%$, and $15.6 \%$ respectively. Three of 90 samples (3.3\%) had one copy of the SULT1A1 gene, while 28 patients (31.1\%) had three or more copies, with the remaining subjects $(65.6 \%)$ having two copies (Table 2). Genotypes frequencies of the population met Hardy-Weinberg equilibrium.

\section{Table 2: CYP2C19, CYP2D6, CYP3A5, AND SULT1A1 genotype frequencies}

\begin{tabular}{|c|c|c|c|c|c|c|c|}
\hline Genotype & Predicted phenotypes & (n) & $\%$ of total & Age (median) & Genotypes & (n) & Genotype frequency \\
\hline \multirow[t]{6}{*}{ CYP2C191 } & $* 2 / * 2$ & (4) & 4.4 & 63 & ${ }^{*} 2 / * 2$ & (4) & 0.03 \\
\hline & $* 1 / * 2$ & $(15)$ & 16.7 & 66 & $* 1 / * 2$ & (15) & 0.21 \\
\hline & ${ }^{*} 1 / * 1$ & (35) & 38.9 & 62 & ${ }^{*} 1 /{ }^{*} 1$ & (35) & 0.35 \\
\hline & ${ }^{*} 1 /{ }^{*} 17$ and ${ }^{*} 2 /{ }^{*} 17$ & (33) & 36.7 & 62 & ${ }^{*} 1 /{ }^{*} 17$ & (24) & 0.27 \\
\hline & & & & & $* 2 /{ }^{*} 17$ & (9) & 0.08 \\
\hline & ${ }^{*} 17 / * 17$ & (3) & 3.3 & 65 & ${ }^{*} 17 / * 17$ & (3) & 0.05 \\
\hline \multirow[t]{8}{*}{ CYP2D6 ${ }^{2}$} & PM & (6) & 6.7 & 65 & $* 4 / * 4$ & (4) & 0.04 \\
\hline & & & & & $* 4 / * 5$ & $(2)$ & 0.01 \\
\hline & $\mathrm{IM}$ & $(32)$ & 35.5 & 55 & $* 1 / * 3$ & (1) & 0.01 \\
\hline & & & & & ${ }^{*} 1 / * 4$ & (27) & 0.29 \\
\hline & & & & & $* 1 / * 5$ & (3) & 0.04 \\
\hline & & & & & ${ }^{*} 1 / * 6$ & (1) & 0.01 \\
\hline & $\mathrm{Wt} / \mathrm{Wt}$ & $(51)$ & 56.7 & 60 & $* 1 / * 1$ & (51) & 0.48 \\
\hline & UM & $(1)$ & 1.1 & 50 & ${ }^{*} 1 / * 2 \times 2$ & (1) & \\
\hline \multirow[t]{3}{*}{ CYP3A5 } & $\mathrm{Vt} / \mathrm{Vt}$ & (76) & 84.4 & 60 & $* 3 / * 3$ & (76) & 0.85 \\
\hline & $\mathrm{Wt} / \mathrm{Vt}$ & (14) & 15.6 & 73 & $* 1 / * 3$ & (14) & 0.50 \\
\hline & $\mathrm{Wt} / \mathrm{Wt}$ & $(0)$ & & & $* 1 / * 1$ & $(0)$ & \\
\hline \multirow[t]{3}{*}{ SULT1A1 } & $\mathrm{Vt} / \mathrm{Vt}$ & (14) & 15.6 & 61 & $* 2 / * 2$ & (14) & 0.11 \\
\hline & $\mathrm{Wt} / \mathrm{Vt}$ & $(32)$ & 35.5 & 59 & $* 1 / * 2$ & (32) & 0.44 \\
\hline & $\mathrm{Wt} / \mathrm{Wt}$ & $(44)$ & 48.9 & 59 & $* 1 / * 1$ & (44) & 0.45 \\
\hline \multirow[t]{5}{*}{ SULT1A1 copy numbers } & 1 & (3) & 3.3 & 59 & & & \\
\hline & 2 & (59) & 65.6 & 60 & & & \\
\hline & 3 & $(21)$ & 23.3 & 67 & & & \\
\hline & 4 & (5) & 5.6 & 72 & & & \\
\hline & 5 & $(2)$ & 2.2 & 69 & & & \\
\hline
\end{tabular}

$1 * 2 /{ }^{*} 2$, subjects homozygous for the variant allele CYP2C19*2; ${ }^{*} 1 /{ }^{*} 2$, subjects heterozygous for the variant allele CYP2C19*2; intermediate metabolizer, subjects homozygous for the wild type allele CYP2C19*1 and with CYP2C $19^{*} 2 / * 17 ; * 1 /{ }^{*} 17$ subjects heterozygous for the CYP2C19*17 variant allele; ${ }^{*} 17{ }^{*} 17 \mathrm{Vt}^{*} 17$ subjects homozygous for the CYP2C19*17 variant allele 2PM, poor metabolizer CYP2D6; IM, intermediate metabolizer wild type/variant type CYP2D6; Wt/Wt, wild type/wild type CYP2D6; UM, ultra rapid metabolizer CYP2D6. 


\section{Serum Levels of Tamoxifen, Estrogens, FSH, and SHBG}

The serum levels of tamoxifen were positively associated with the serum levels of E2 and E1 $(R=0.295$, and 0.297, $\mathrm{p}=0.025$ and $\mathrm{p}=0.020$, respectively, Table 3 ). A positive association was also observed between tamoxifen and E1S $(R=0.254, p=0.08$, Table 3$)$, although it did not reach a level of statistical significance. As shown in Table 3 , positive associations were also observed between the serum levels of NDDtam with E2 and E1 $(R=0.315$ and $R$ $=0.330, \mathrm{p}=0.01$ and $\mathrm{p}=0.005$, respectively), and tamNox with $E 1$ and $E 1 S(R=0.292$ and $R=0.284, p=0.025$ and $p$ $=0.035$, respectively). Furthermore, the serum concentration of 4OHNDtam was associated with the serum level of FSH $(R=0.269, p=0.05)$. To minimize a possible effect of CYP2D6 allele variation and to keep a homogenous group, this association was also examined among patients homozygous for the CYP2D6 Wt allele $(\mathrm{R}=0.386, \mathrm{p}=$ $0.025)$. We also observed a negative association between the serum level of E1S (Table 3) and SHBG $(R=-0.445$, p $<0.01)$.

\section{CYP2C19 Genotype}

The CYP2C19 genotype predicted enzymatic activity was negatively associated with the serum levels of NDDtam and tamNox $(\mathrm{p}=0.022$ and $\mathrm{p}=0.002$, respectively) as shown in Table 4. Studying the metabolic ratios of tamoxifen and its metabolites, $4 \mathrm{OHtam}$ to tamoxifen (4OHtam/ tam) increased with increasing CYP2C19 predicted activity $(\mathrm{p}=0.004$, figure $2 \mathrm{~A})$ whereas no difference was observed between CYP2C19 genotypes and the metabolic ratio of $4 \mathrm{OHNDtam}$ to NDtam $(\mathrm{p}=0.226$, figure 2B). As for the tamNox to tamoxifen ratio was inversely related with CYP2C19 predicted activity $(\mathrm{p}=0.001$, figure $2 \mathrm{C}$ ). In contrast the NDtam to tamNox ratio it increased with increasing CYP2C19 predicted activity ( $\mathrm{p}$ $<0.001$, figure 2D).

Of the 15 individuals with predicted low CYP2C19"1/"2 enzymatic activity, 1 had CYP2D6 PM status, 5 IM status, $8 \mathrm{Wt} / \mathrm{Wt}$ status, and $1 \mathrm{UM}$ status. In this CYP2C19*1/*2 subgroup, we observed no significant difference for the $4 \mathrm{OHtam} /$ tam ratio between the groups based on CYP2D6 status ( $\mathrm{p}=0.932$, data not shown). Furthermore, 35 individuals had CYP2C19*1/*1, of these 2 had PM status, $11 \mathrm{IM}$ status, and $22 \mathrm{Wt} / \mathrm{Wt}$ status. There was a positive association between the ratio of $4 \mathrm{OHtam} / \mathrm{tam}$ and CYP2D6 gene dose effect ( $\mathrm{p}=0.036$, data not shown). Moreover, we observed 33 individuals heterozygous for the CYP2C19*17 allele, of these 1 with PM status, 16 CYP2D6 IM status, and 16 CYP2D6 Wt/Wt status. There was also no significant difference for $4 \mathrm{OHtam} / \mathrm{tam}$ observed between these groups $(\mathrm{p}=0.403)$. Thus, our results suggest that CYP2D6 status does affect the ratio of $4 \mathrm{OHtam} / \mathrm{tam}$ only in subjects with normal CYP2C19 activity, but not in the subjects carrying CYPC19 "17 allele.

Studying the influence of CYP2C19 genotypes on estrogen metabolism we observed a negative association between increased CYP2C19 predicted enzymatic activity and E1 (Table 5). Lower serum levels of E1 was observed in patients either heterozygous or homozygous carriers of the CYP2C19*17 allele when compared with patients either heterozygous or homozygous for the CYP2C19*2 allele $(\mathrm{p}=0.019)$, as shown in Table 5 . No

Table 3: Associations between the serum concentrations of tamoxifen, estrogens, FSH' ${ }^{\text {, and }}$ SHBG

\begin{tabular}{|c|c|c|c|c|c|c|c|}
\hline Variables & Tamoxifen & 40Htam & 4OHNDtam & NDtam & NDDtam & TamNox & SHBG \\
\hline All $(n=90)$ & $r$ & $r$ & $r$ & $r$ & $r$ & $r$ & $r$ \\
\hline E2 & $0.295^{*}$ & 0.131 & 0.211 & 0.148 & $0.315^{* *}$ & 0.232 & -0.048 \\
\hline E1 & $0.297^{*}$ & 0.133 & 0.152 & 0.226 & $0.330^{* *}$ & $0.292^{*}$ & -0.002 \\
\hline E1S & 0.254 & 0.119 & 0.118 & 0.247 & 0.194 & $0.284^{*}$ & $-0.445^{* *}$ \\
\hline FSH & 0.118 & 0.065 & $0.269 *$ & 0.134 & 0.031 & 0.178 & 0.095 \\
\hline SHBG & -0.027 & 0.034 & 0.088 & 0.000 & 0.048 & 0.103 & \\
\hline
\end{tabular}

Wt/Wt EM

CYP2D6 $(\mathrm{n}=$

51)

FSH

0.151

0.133

$0.386^{*}$

0.148

0.133

0.259

0.224

${ }^{1} \mathrm{FSH}$, Follicle Stimulating Hormone; SHBG, sex hormone binding globulin; 4OHtam, 4-hydroxytamoxifen; 4OHNDtam, 4-hydroxy-Ndemethyltamoxifen; NDtam, N-demethyltamoxifen; NDDtam, N-dedimethyltamoxifen; tamNox, tamoxifen-N-oxide; r, coefficient; E2, estradiol; E1, estrone; E1S, estrone sulfate; $\mathrm{Wt} / \mathrm{Wt}$ EM, wild type/wild type extensive metabolizer CYP2D6.

$r$ and $p$ values are derived from two-tailed Spearman correlation rank test. The $p$-values are given after Bonferroni correction for multiple $(n=5)$ comparisons within this data set, ${ }^{*} p<0.05$, and ${ }^{* *} p<0.01$. 

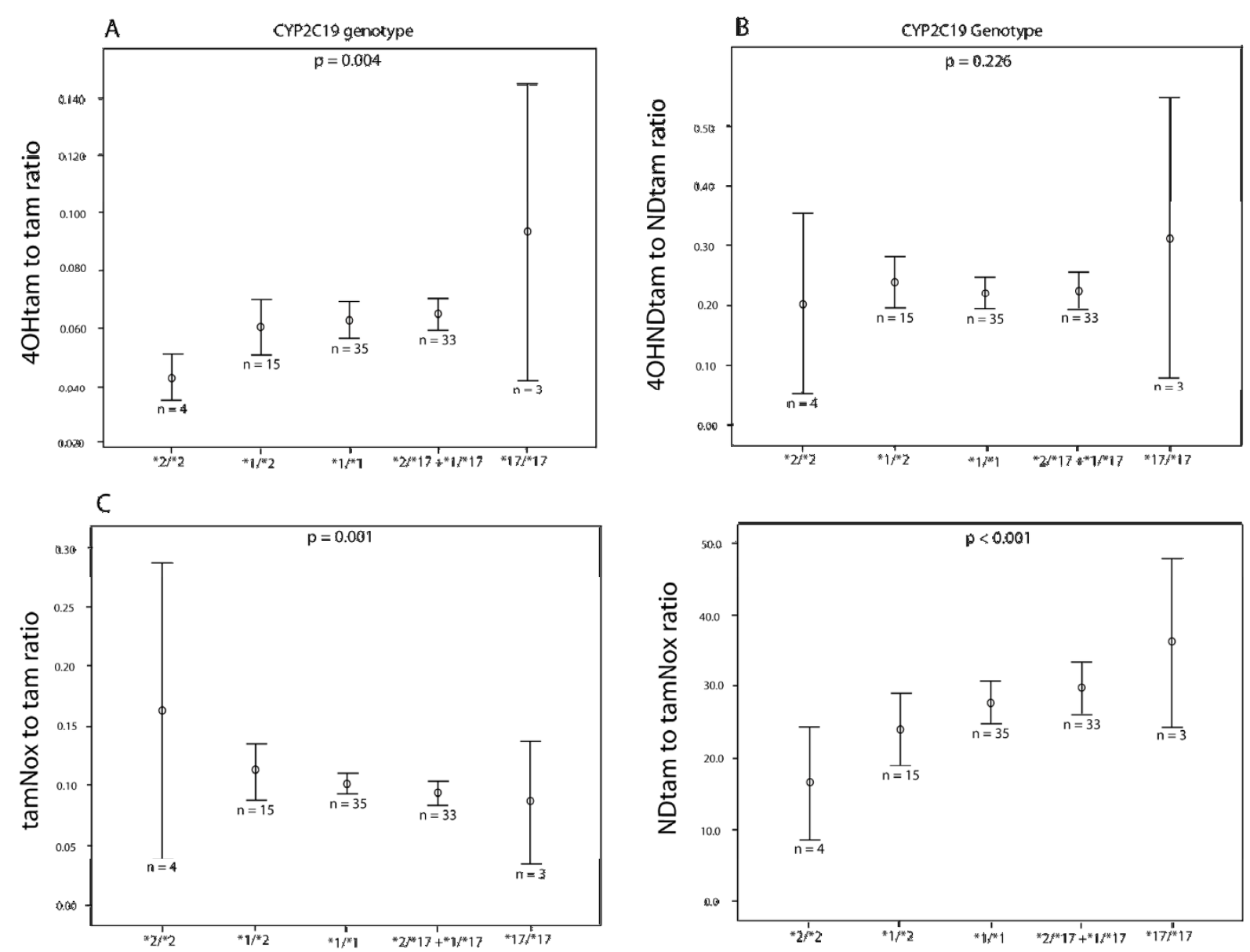

Figure 2 Relationships between the CYP2C19 genotype and metabolic ratios of $40 \mathrm{OHtam} / \mathrm{tam}, 40 \mathrm{HNDtam} / \mathrm{NDtam}$, tamNox/tam, and NDtam/tamNox. Error bars represent $95 \%$ confidence interval. ${ }^{2} 2{ }^{*} 2$, encodes defective CYP2C19 activity; Vt*17, subjects heterozygous for the variant type allele CYP2C19*17 $\left({ }^{*} 1 /{ }^{*} 17\right.$ and $\left.{ }^{*} 2{ }^{*} 17\right) ;{ }^{*} 17 /{ }^{*} 17$, encodes ultra rapid CYP2C19 activity.

associations were observed between FSH, SHBG and CYP2C19 (data not shown).

\section{CYP2D6 Genotype}

We have shown earlier that CYP2D6 genotypes influenced tamoxifen kinetics in a dose dependent manner [7]. In this sub-group of postmenopausal women, we observed positive relations between the serum levels of 4OHtam and 4OHNDtam and CYP2D6 gene dose effect $(\mathrm{p}=0.019$ and $\mathrm{p}=0.009$, respectively, Table 4$)$. In contrast, NDtam was inversely associated with CYP2D6 predicted increasing activity $(\mathrm{p}=0.044)$. We observed no relationship between the serum levels of estrogens and CYP2D6 genotypes (Table 5), and no associations were observed between FSH, SHBG and CYP2D6 (data not shown).

\section{CYP3A5 Genotype}

We also examined the association between the CYP3A5 genotypes and serum levels of tamoxifen and its metabo- lites. The median serum concentration of tamNox was lower for patients homozygous for the CYP3A $5 * 3$ allele than heterozygous CYP3A 5*1/*3, $(\mathrm{p}=0.04$, Table 4$)$. The same trend was observed in the serum levels of $4 \mathrm{OHtam}$, NDtam and NDDtam, although these did not reach significant values $(\mathrm{p}=0.074, \mathrm{p}=0.075$ and $\mathrm{p}=0.052$, respectively). There was no association observed between the serum concentrations of E2, E1, E1S, and the CYP3A5 genotypes (Table 5). The same were observed between FSH, SHBG and CYP3A5 (data not shown).

\section{SULT1A1 Genotype}

No association between the serum levels of tamoxifen and its metabolites and the SULT1A1 genotypes was demonstrated in this subgroup of postmenopausal women. The serum concentrations of E2, E1, and E1S were not associated with SULT1A1 allele variation (Table 5). However SULT1A1 copy number was positively associated with the serum levels of E2, E1, and E1S ( $p=0.024$, $\mathrm{p}=0.010$, and $\mathrm{p}=0.005$; respectively). The SULT1A1 


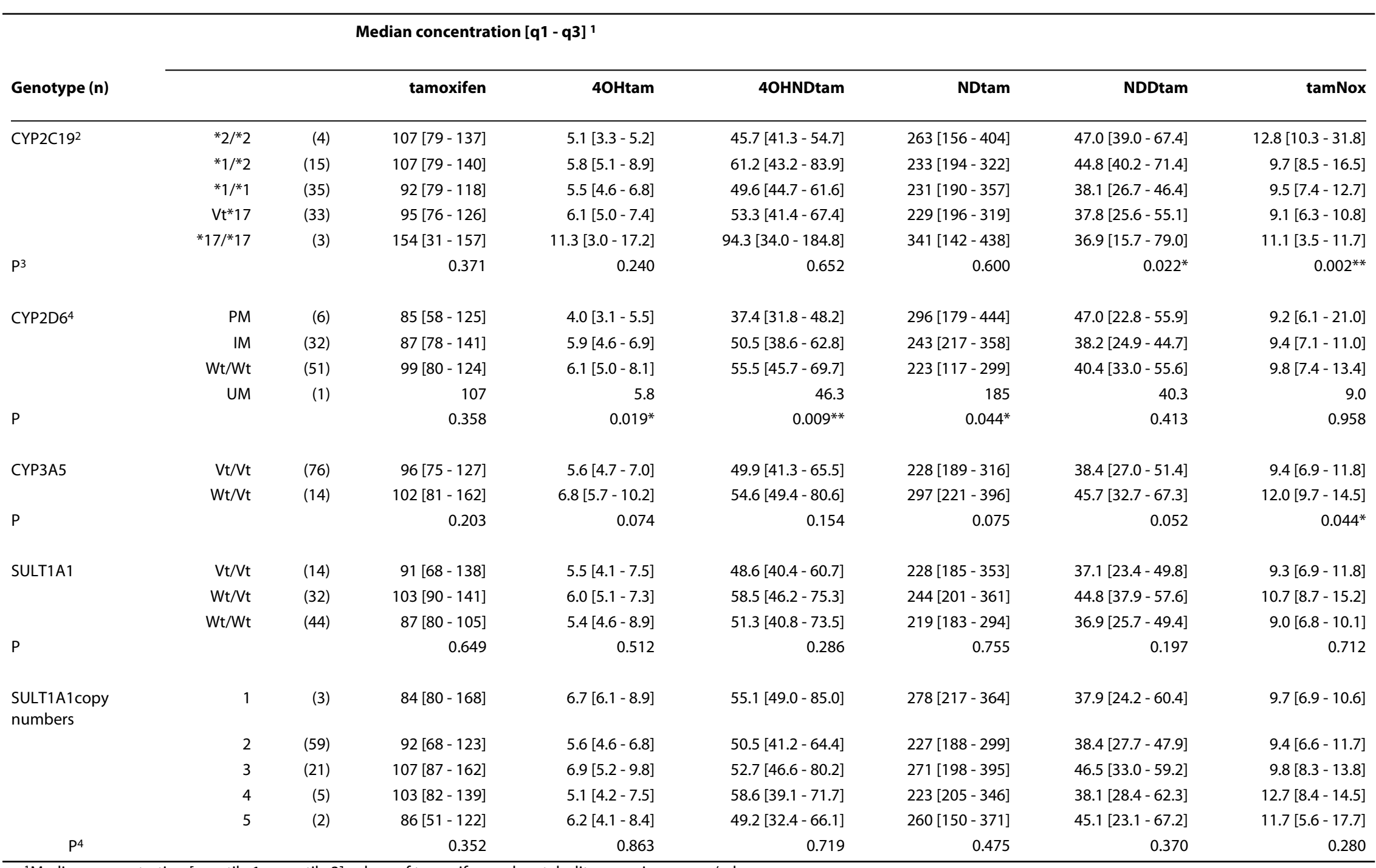

${ }^{1}$ Median concentration [quartile 1 - quartile 3] values of tamoxifen and metabolites are given as $\mathrm{ng} / \mathrm{ml}$.

$2 * 2 / * 2$, encodes defective CYP2C19 activity; Vt*17, subjects heterozygous for the variant type allele CYP2C19*17 $\left({ }^{*} 1 /{ }^{*} 17\right.$ and $\left.* 2 /{ }^{*} 17\right) ; * 17 /{ }^{*} 17$, encodes ultra rapid CYP2C19 activity

${ }^{3 P}$ values were calculated by multivariate logistic regression model, ${ }^{*} \mathrm{p}<0.05$. Adjusted for CYP2C19, CYP2D6, CYP3A5, SULT1A1, SULT1A1 copy number, FSH and SHBG.

4PM, poor metabolizer; IM, wild type/variant type; Wt/Wt, wild type/wild type; UM, ultra rapid metabolizer. 
Table 5: Relations between CYP2C19, CYP2D6, CYP3A5 and SULT1A1 genotypes and estrogens in postmenopausal women $(\mathbf{n}=90)$

Median concentration [q1 - q3] 1

\begin{tabular}{|c|c|c|c|c|c|}
\hline Genotype (n) & & & E1 & E2 & E1S \\
\hline \multirow[t]{5}{*}{ CYP2C192 } & $* 2 / * 2$ & (4) & $122[88-303]$ & $9.6[6.7-43.5]$ & 857 [309 - 1400] \\
\hline & $* 1 / * 2$ & (15) & $106[72-182]$ & $13.0[6.6-32.0]$ & 391 [234 - 955] \\
\hline & ${ }^{*} 1 / * 1$ & (35) & $102[70-124]$ & $10.9[5.7-16.0]$ & 655 [345 - 928] \\
\hline & $\mathrm{Vt}^{*} 17$ & (33) & $86[66-104]$ & $8.4[6.0-12.1]$ & $545[259-801]$ \\
\hline & ${ }^{*} 17 / * 17$ & (3) & $75[54-122]$ & $9.3[9.3-17.4]$ & $428[158-654]$ \\
\hline \multicolumn{2}{|l|}{$\mathrm{P}^{3}$} & & $0.019^{*}$ & 0.139 & 0.227 \\
\hline \multirow[t]{4}{*}{ CYP2D6 4} & PM & (6) & 111 [96 - 154] & $9.4[6.6-24.4]$ & 491 [318 - 878] \\
\hline & $\mathrm{IM}$ & (32) & $91[66-111]$ & $7.7[5.2-14.1]$ & $595[255-931]$ \\
\hline & Wt/Wt & (51) & $101[67-128]$ & $10.9[6.1-17.4]$ & 588 [345 - 888] \\
\hline & UM & (1) & 72 & 6.6 & 391 \\
\hline $\mathrm{P}$ & & & 0.559 & 0.938 & 0.804 \\
\hline \multirow[t]{2}{*}{ CYP3A5 } & $\mathrm{Vt} / \mathrm{Vt}$ & (76) & 99 [71 - 123] & $10.5[6.6-16.4]$ & 569 [305 - 865] \\
\hline & $\mathrm{Wt} / \mathrm{Vt}$ & (14) & $97[65-124]$ & $8.0[4.3-10.5]$ & 631 [294 - 1127] \\
\hline $\mathrm{P}$ & & & 0.520 & 0.248 & 0.221 \\
\hline \multirow[t]{3}{*}{ SULT1A1 } & $\mathrm{Vt} / \mathrm{Vt}$ & (14) & 80.6 [66.4- 103.5] & $6.7[5.2-9.4]$ & 590.4 [316.5- 851.1] \\
\hline & $\mathrm{Wt} / \mathrm{Vt}$ & (32) & 99.1 [68.6-121.7] & $13.7[5.3-18.9]$ & 537.0 [318.0- 768.7] \\
\hline & $\mathrm{Wt} / \mathrm{Wt}$ & (44) & $102.1[70.9-142.1]$ & $9.4[1.4-54.7]$ & 608.5 [135.6-2922.9] \\
\hline$P$ & & & 0.280 & 0.575 & 0.734 \\
\hline \multirow[t]{5}{*}{ SULT1A1 copy numbers } & 1 & (3) & $59.7[58.7-101.2]$ & $3.8[2.6-6.5]$ & 252.9 [235.5- 939.0] \\
\hline & 2 & (59) & $89.8[67.2-110.2]$ & $7.7[5.5-15.2]$ & 498.4 [271.6- 758.9] \\
\hline & 3 & (21) & 105.7 [90.7-128.6] & $11.8[9.0-14.3]$ & 859.5 [561.3- 955.2] \\
\hline & 4 & (5) & $101.8[98.0-103.0]$ & $15.3[12.6-19.1]$ & $363.6[227.5-662.0]$ \\
\hline & 5 & (2) & 157.6 [155.3-160.0] & $13.6[9.4-17.9]$ & 2086.3 [1780.7-2391.9] \\
\hline $\mathrm{P}$ & & & $0.024^{*}$ & $0.010^{*}$ & $0.005^{* *}$ \\
\hline
\end{tabular}

1 Median concentration [quartile 1 - quartile 3] values of tamoxifen and metabolites are given as $\mathrm{ng} / \mathrm{ml}$.

$2 * 2 /{ }^{*} 2$, encodes defective CYP2C19 activity; $\mathrm{Vt} * 17$, subjects heterozygous for the variant type allele CYP2C19*17 $\left({ }^{*} 1 /^{*} 17\right.$ and $\left.{ }^{*} 2 /{ }^{*} 17\right) ;{ }^{*} 17 /{ }^{*} 17$, encodes ultra rapid CYP2C19 activity.

${ }^{3 P}$ values were calculated by multivariate logistic regression model, ${ }^{*} p<0.05$. Adjusted for CYP2C19, CYP2D6, CYP3A5, SULT1A1, SULT1A1 copy number, FSH and SHBG.

4PM, poor metabolizer; IM, wild type/variant type; Wt/Wt, wild type/wild type; UM, ultra rapid metabolizer.

genotypes did not influence FSH and SHBG (data not shown).

\section{Discussion}

In this study we used two highly sensitive assays for measuring the serum levels of tamoxifen and its metabolites and estrogens [28,29]. As hypothesized, we observed pos- itive associations between the serum levels of estrogens (E1 and E2) and tamoxifen, as well as two of its' nonhydroxylated metabolites (NDDtam and tamNox). Interestingly, the concentrations of the more potent hydroxylated tamoxifen metabolites (4OHtam and 4OHNDtam) were not correlated to estrogen levels. 
Metabolites of tamoxifen that are not hydroxylated may also contribute to the effects or adverse effects of tamoxifen. NDtam, NDDtam and tamNox have estrogen receptor affinity that is the same as for tamoxifen itself but which is 100-fold lower than 4OHtam and 4OHNDtam $[2,31,32]$. Notably, high levels of NDtam and NDDtam have been reported in patients experiencing tamoxifenrelated side effects [33,34]. In animals NDDtam appears to decrease the rate of tamoxifen metabolism [35] whereas tamNox may represent a pool for its' reconversion back to tamoxifen [36]. The roles of NDtam, NDDtam, and tamNox in the clinical situation remain to be explored more in detail.

Dowsett et al suggests that tamoxifen effectively saturates ER during tamoxifen of postmenopausal women [31]. This may suggest that estrogen levels during tamoxifen therapy may have limited importance. However, long term exposure to tamoxifen has been shown to induce a state of adaptive hypersensitivity in breast tumors to E2 [22]. Thus, upon development of tamoxifen resistance, low levels of estrogen may stimulate tumor growth. Moreover, clinical studies have shown that the expression of $17 \beta$-hydroxysteroid dehydrogenase 1 (17HSD1), which converts E1 to the active estrogen E2, and 17HSD2, which converts E2 to E1, are predictive factors for treatment response to tamoxifen in both premenopausal and postmenopausal patients $[37,38]$. These suggest that estrogen levels may be of importance during long term tamoxifen therapy.

Tamoxifen and estrogens are both partly metabolized by the enzymes CYP2C19, 2D6, 3A5, and SULT1A1 [27]. Therefore, we screened for associations between these genotypes and estrogen serum levels and observed that the predicted CYP2C19 activity was related to the level of E1. This should be expected as only E1 and not E2 or E1S is converted by CYP2C19 (figure 1B). Patients carrying the CYP2C19*17 allele predicting high enzyme activity had lower serum levels of E1 compared with those carrying CYP2C19 defective alleles. This finding is in agreement with a recent report suggesting that an increased catabolism of estrogens by CYP2C19 may lead to decreased estrogen levels and therefore reduced breast cancer risk [39], and the observation that CYP2C19*17 identifies patients likely to benefit from tamoxifen treatment [19].

The 4OHtam to tamoxifen ratio was positively associated with increasing $\mathrm{CYP} 2 \mathrm{C} 19$ predicted enzymatic activity, whereas no such correlation was observed for the ratio of $4 \mathrm{OHNDtam}$ to NDtam. This is consistent with previous reports showing that CYP2C19 hydroxylates tamoxifen, but not NDtam [40]. Of note is the finding that the metabolic ratio NDtam/tamNox was highly significantly related to the predicted activity of CYP2C19. This is in line with the suggestion of Jordan et al that tam-
Nox represents an intermediate metabolic step between tamoxifen and NDtam [41].

The predicted CYP2D6 and CYP3A5 activities did not influence estrogen levels, whereas SULT1A1 gene copy number was positively related to the levels of E2, E1, and E1S, but not to those of tamoxifen or its metabolites. A novel finding in the present study was the observation of lower serum levels of tamNox in patients homozygous for the low activity allele CYP3A $5 * 3$ compared to patients heterozygous for this allele. Although not significant there was also a trend for lower levels of 4OHtam, NDtam and NDDtam. This was expected since CYP3A5 hydroxylates and demethylates tamoxifen (figure 1A). Wegman et al observed, in contrast to Goetz et al, that patients homozygous for CYP3A $5 * 3$ have improved recurrence free-survival $[18,25]$. The clinical importance of CYP3A 5 in this matter remains unanswered.

The observed associations between the kinetics of tamoxifen and the levels of estrogens may be due to competition between tamoxifen or its metabolites and estrogens to be processed by identical enzymes such as CYP2C19. An alternative explanation is that tamoxifen and its metabolites inhibit enzymes that are involved in the degradation of estrogens. This is line with the finding of Meltzer et al who demonstrated that tamoxifen and NDtam may act both competitively and non-competitively on microsomal mixed function oxidases [42]. Another explanation is that the associations may also be a consequence of the observed increase of serum levels of dehydroepiandrosterone (DHEA) during tamoxifen treatment therapy $[43,44]$. DHEA can be converted to androstendione which is a precursor of estrogens. Both tamoxifen and estrogens are also excreted in bile as conjugates. After deconjugation by intestinal microflora they are partly reabsorbed resulting in pronounced enterohepatic cycling $[45,46]$. Accordingly, the deconjugation capacity of the microflora in the intestines may be a common determinant for their re-absorption and bioavailability $[6,47]$.

We have observed estrogen agonistic effects of tamoxifen in the liver and in the pituitary gland of postmenopausal patients [48]. The serum level of SHBG was more than doubled and the level of FSH was almost halved. To be certain that tamoxifen levels were in steady-state in the present study all patients included were treated with tamoxifen for at least 80 days. After this treatment period we believe that also estrogen levels were at steady state levels. Although tamoxifen exerts an estrogen agonistic effect on the pituitary of postmenopausal women, we do not know the separate effects of each of its metabolites on the pituitary. Therefore, it is interesting that of the five tamoxifen metabolites examined, only the serum concentrations of $4 \mathrm{OHNDtam}$ was positively associated with the serum levels of FSH in this situation of steady-state 
tamoxifen kinetics. This suggests that 4OHNDtam has an anti-estrogenic effect in the pituitary gland.

Hot flashes have been suggested as a predictor of tamoxifen efficacy [26]. Of note, FSH serum concentrations correspond better with the frequency of hot flashes than the levels of E2 [23]. Interestingly, some results from clinical studies suggest that patients carrying functional CYP2D6 alleles have a higher incidence of hot flashes, higher levels of 4OHNDtam and better outcome during tamoxifen treatment [25,26]. Accordingly, relations between the frequency of hot flashes, serum concentrations of 4OHNDtam and outcome during tamoxifen therapy may exist.

Limitations of the present study are that the correlations observed are weak and we have not had admittance to patient journals and do not know of any additional drug use. However, we and others have observed that breast cancer patients often use several additional drugs that may interact with tamoxifen [49-52]. Accordingly, the weak correlations observed are not surprising as drugs, enzymes and other factors in addition to those analyzed in the present study may interact with the metabolism of tamoxifen as well as that of estrogens.

\section{Conclusions}

We have shown an association between the non-hydroxylated metabolites of tamoxifen and estrogen serum levels. The influence of CYP2C19 predicted activity on tamoxifen and estrogen kinetics may partly explain this observation. Thus estrogens as well as tamoxifen metabolites may influence the observed tamoxifen treatment benefit of patients carrying CYP2C19 *17 variant. In addition, the more potent hydroxylated tamoxifen metabolite 4OHNDtam (endoxifen) was the only tamoxifen metabolite positively associated with FSH levels suggesting antiestrogenic effect on the pituitary. This may explain the observed positive association between a better prognosis and FSH levels during tamoxifen therapy. Our results may be of importance for the effects, side effects, timing and duration of tamoxifen treatment. Further prospective studies to examine the effect of tamoxifen and estrogen kinetics on treatment outcome are therefore warranted.

\section{Competing interests}

The authors declare that they have no competing interests.

\section{Authors' contributions}

$J G^{1}$ conceived the study, participated in the design of the study, performed the quantifications of tamoxifen and metabolites, CYP2C19 and SULT1A1 genotyping, statistical analysis of the data and drafted the manuscript. JG and DE participated in performing estrogen measurements and drafted the manuscript. SL and JEV conceived the study, participated in the design of the study, collected the materials and drafted the manuscript. VMS conceived the study, participated in the design of the study, performed the CYP2D6 genotyping, statistical analysis of the data and drafted the manuscript. GM and EAL conceived the study, participated in the design of the study, statistical analysis of the data and drafted the manuscript. All authors read and approved the final manuscript.

\section{Acknowledgements}

This work was supported in part by the Norwegian Cancer Society; the Research Council of Norway; the Dr Einar Martens Foundation; the Grieg Foundation; and the Frank Mohn Foundation. We thank Dr. Geirfinn Vagstad for help with providing the serum samples from Førde Central Hospital, Herdis Tveiten and Johannes Aursland for technical support, and Carol Cook for proof-reading the manuscript.

\section{Author Details}

1 Hormone Laboratory, Haukeland University Hospital, Bergen, N-5021, Norway, 2Section for Endocrinology, Institute of Medicine, University of Bergen, Bergen, N-5021, Norway, ${ }^{3}$ Department of Oncology, Haukeland University Hospital, Bergen, N-5021, Norway, 4 Section for Oncology, Institute of Medicine, University of Bergen, Bergen, N-5021, Norway; Faculty Division Akerhus University Hospital, University of Oslo, Oslo, N-0316, Norway, ${ }^{5}$ Section of Oncology, Department of Medicine, Akershus University Hospital, Lørenskog, $\mathrm{N}-1478$, Norway, ${ }^{6}$ Department of Oncology, St. Olavs University Hospital, Trondheim, N-7006, Norway, ${ }^{7}$ Department of Cancer Research and Molecular Medicine, Faculty of Medicine, Norwegian University of Science and Technology, Trondheim, N-7006, Norway, ${ }^{8}$ Department of Surgery, Haukeland University Hospital, Bergen, N-5021, Norway, ${ }^{9}$ Department of Surgical Sciences, University of Bergen, Bergen, N-5021, Norway, ${ }^{10}$ Dr. E. Martens Research Group for Biological Psychiatry, Department of Clinical Medicine, University of Bergen, Bergen, N-5021, Norway and ${ }^{11}$ Center for Medical Genetics and Molecular Medicine, Haukeland University Hospital, Bergen, N5021, Norway

Received: 11 February 2010 Accepted: 21 June 2010 Published: 21 June 2010

\section{References}

1. MacGregor Jl, Jordan VC: Basic guide to the mechanisms of antiestrogen action. Pharmacol Rev 1998, 50(2):151-196.

2. Katzenellenbogen BS, Norman MJ, Eckert RL, Peltz SW, Mangel WF Bioactivities, estrogen receptor interactions, and plasminogen activator-inducing activities of tamoxifen and hydroxy-tamoxifen isomers in MCF-7 human breast cancer cells. Cancer Res 1984, 44(1):112-119.

3. Johnson MD, Zuo H, Lee KH, Trebley JP, Rae JM, Weatherman RV, Desta Z, Flockhart DA, Skaar TC: Pharmacological characterization of 4-hydroxy$\mathrm{N}$-desmethyl tamoxifen, a novel active metabolite of tamoxifen. Breast cancer research and treatment 2004, 85(2):151-159.

4. Borgna $\mathrm{J}$, Rochefort $\mathrm{H}$ : Hydroxylated metabolites of tamoxifen are formed in vivo and bound to estrogen receptor in target tissues. $\mathrm{JBiO}$ Chem 1981, 256(2):859-868.

5. Lien EA, Solheim E, Kvinnsland S, Ueland PM: Identification of 4-hydroxy$\mathrm{N}$-desmethyltamoxifen as a metabolite of tamoxifen in human bile. Cancer research 1988, 48(8):2304-2308.

6. Lien EA, Solheim E, Lea OA, Lundgren S, Kvinnsland S, Ueland PM: Distribution of 4-hydroxy-N-desmethyltamoxifen and other tamoxifen metabolites in human biological fluids during tamoxifen treatment. Cancer research 1989, 49(8):2175-2183.

7. Gjerde J, Hauglid M, Breilid H, Lundgren S, Varhaug JE, Kisanga ER, Mellgren G, Steen VM, Lien EA: Effects of CYP2D6 and SULT1A1 genotypes including SULT1A1 gene copy number on tamoxifen metabolism. Ann Oncol 2008, 19(1):56-61.

8. Desta Z, Ward BA, Soukhova NV, Flockhart DA: Comprehensive evaluation of tamoxifen sequential biotransformation by the human cytochrome P450 system in vitro: prominent roles for CYP3A and CYP2D6. J Pharmacol Exp Ther 2004, 310(3):1062-1075.

9. Nishiyama T, Ogura K, Nakano H, Ohnuma T, Kaku T, Hiratsuka A, Muro K Watabe T: Reverse geometrical selectivity in glucuronidation and sulfation of cis- and trans-4-hydroxytamoxifens by human liver UDPglucuronosyltransferases and sulfotransferases. Biochem Pharmacol 2002, 63(10):1817-1830

10. Wegman P, Vainikka L, Stål O: Genotype of metabolic enzymes and the benefit of tamoxifen in postmenopausal breast cancer patients. Breast Cancer Res 2005, 7(3):284-290.

11. Okishiro M, Taguchi T, Jin Kim S, Shimazu K, Tamaki Y, Noguchi S: Genetic polymorphisms of CYP2D6 10 and CYP2C19 2, 3 are not associated with prognosis, endometrial thickness, or bone mineral density in 
Japanese breast cancer patients treated with adjuvant tamoxifen. Cancer 2009, 115(5):952-961.

12. Xu Y, Sun Y, Yao L, Shi L, Wu Y, Ouyang T, Li J, Wang T, Fan Z, Fan T, Lin B, He L, Li P, Xie Y: Association between CYP2D6 *10 genotype and survival of breast cancer patients receiving tamoxifen treatment. Ann Oncol 2008, 19(8):1423-1429.

13. Kiyotani K, Mushiroda T, Sasa M, Bando Y, Sumitomo I, Hosono N, Kubo M, Nakamura Y, Zembutsu H: Impact of CYP2D6*10 on recurrence-free survival in breast cancer patients receiving adjuvant tamoxifen therapy. Cancer Sci 2008, 99(5):995-999.

14. Nowell SA, Ahn J, Rae JM, Scheys JO, Trovato A, Sweeney C, MacLeod SL, Kadlubar FF, Ambrosone CB: Association of genetic variation in tamoxifen-metabolizing enzymes with overall survival and recurrence of disease in breast cancer patients. Breast cancer research and treatment 2005, 91(3):249-258.

15. Ramon YCT, Altes A, Pare L, Del Rio E, Alonso C, Barnadas A, Baiget M: Impact of CYP2D6 polymorphisms in tamoxifen adjuvant breast cancer treatment. Breast Cancer Res Treat 2009.

16. Newman WG, Hadfield KD, Latif A, Roberts SA, Shenton A, McHague C, Lalloo F, Howell S, Evans DG: Impaired tamoxifen metabolism reduces survival in familial breast cancer patients. Clin Cancer Res 2008, 14(18):5913-5918

17. Goetz MP, Knox SK, Suman VJ, Rae JM, Safgren SL, Ames MM, Visscher DW, Reynolds C, Couch FJ, Lingle WL, Weinshilboum RM, Fritcher EG, Nibbe AM, Desta Z, Nguyen A, Flockhart DA, Perez EA, Ingle JN: The impact of cytochrome P450 2D6 metabolism in women receiving adjuvant tamoxifen. Breast cancer research and treatment 2007, 101(1):113-121.

18. Wegman $P$, Elingarami $S$, Carstensen J, Stal $O$, Nordenskjold B, Wingren S: Genetic variants of CYP3A5, CYP2D6, SULT1A1, UGT2B15 and tamoxifen response in postmenopausal breast cancer patients. Breast Cancer Res 2007, 9(1):R7.

19. Schroth W, Antoniadou L, Fritz P, Schwab M, Muerdter T, Zanger UM, Simon W, Eichelbaum M, Brauch H: Breast cancer treatment outcome with adjuvant tamoxifen relative to patient CYP2D6 and CYP2C19 genotypes. J Clin Oncol 2007, 25(33):5187-5193.

20. Lash TL, Lien EA, Sorensen HT, Hamilton-Dutoit S: Genotype-guided tamoxifen therapy: time to pause for reflection? Lancet Oncol 2009, 10(8):825-833.

21. Lewis JS, Jordan VC: Selective estrogen receptor modulators (SERMs): mechanisms of anticarcinogenesis and drug resistance. Mutat Res 2005, 591(1-2):247-263.

22. Berstein LM, Wang JP, Zheng H, Yue W, Conaway M, Santen RJ: Long-term exposure to tamoxifen induces hypersensitivity to estradiol. Clin Cancer Res 2004, 10(4):1530-1534.

23. Randolph JF Jr, Sowers M, Bondarenko I, Gold EB, Greendale GA Bromberger JT, Brockwell SE, Matthews KA: The relationship of longitudinal change in reproductive hormones and vasomotor symptoms during the menopausal transition. J Clin Endocrinol Metab 2005, 90(11):6106-6112

24. Huang AJ, Grady D, Jacoby VL, Blackwell TL, Bauer DC, Sawaya GF: Persistent hot flushes in older postmenopausal women. Arch Intern Med 2008, 168(8):840-846.

25. Goetz MP, Rae JM, Suman VJ, Safgren SL, Ames MM, Visscher DW, Reynolds C, Couch FJ, Lingle WL, Flockhart DA, Desta Z, Perez EA, Ingle JN: Pharmacogenetics of tamoxifen biotransformation is associated with clinical outcomes of efficacy and hot flashes. J Clin Oncol 2005, 23(36):9312-9318.

26. Mortimer JE, Flatt SW, Parker BA, Gold EB, Wasserman L, Natarajan L, Pierce JP: Tamoxifen, hot flashes and recurrence in breast cancer. Breast cancer research and treatment 2008, 108(3):421-426

27. Lee AJ, Cai MX, Thomas PE, Conney AH, Zhu BT: Characterization of the oxidative metabolites of 17 beta-estradiol and estrone formed by 15 selectively expressed human cytochrome p450 isoforms. Endocrinology 2003, 144(8):3382-3398.

28. Gjerde J, Kisanga ER, Hauglid M, Holm PI, Mellgren G, Lien EA: Identification and quantification of tamoxifen and four metabolites in serum by liquid chromatography-tandem mass spectrometry. $J$ Chromatogr A 2005, 1082(1):6-14.

29. Geisler J, Ekse D, Helle H, Duong NK, Lönning PE: An optimised, highly sensitive radioimmunoassay for the simultaneous measurement of estrone, estradiol and estrone sulfate in the ultra-low range in human plasma samples. The Journal of steroid biochemistry and molecular biology 2008, 109(1-2):90-95.

30. Hebbring SJ, Adjei AA, Baer JL, Jenkins GD, Zhang J, Cunningham JM, Schaid DJ, Weinshilboum RM, Thibodeau SN: Human SULT1A1 Gene: Copy Number Differences and Functional Implications. Hum Mol Genet 2007, 16(5):463-470

31. Dowsett M, Haynes BP: Hormonal effects of aromatase inhibitors: focus on premenopausal effects and interaction with tamoxifen. J Steroid Biochem Mol Biol 2003, 86(3-5):255-263.

32. Kool J, Ramautar R, van Liempd SM, Beckman J, de Kanter FJ, Meerman JH, Schenk T, Irth H, Commandeur JN, Vermeulen NP: Rapid on-line profiling of estrogen receptor binding metabolites of tamoxifen. J Med Chem 2006, 49(11):3287-3292.

33. Peyrade F, Frenay M, Etienne MC, Ruch F, Guillemare C, Francois E, Namer M, Ferrero JM, Milano G: Age-related difference in tamoxifen disposition. Clin Pharmacol Ther 1996, 59(4):401-410.

34. Gallicchio L, Lord G, Tkaczuk K, Danton M, Lewis LM, Lim CK, Flaws JA: Association of tamoxifen (TAM) and TAM metabolite concentrations with self-reported side effects of TAM in women with breast cancer. Breast cancer research and treatment 2004, 85(1):89-97.

35. Gamboa da Costa G, Marques MM, Fu X, Churchwell MI, Wang YP, Doerge DR, Beland FA: Effect of N,N-didesmethyltamoxifen upon DNA adduct formation by tamoxifen and alpha-hydroxytamoxifen. Cancer Lett 2007, 257(2):191-198.

36. Parte $\mathrm{P}$, Kupfer $\mathrm{D}$ : Oxidation of tamoxifen by human flavin-containing monooxygenase (FMO) 1 and FMO3 to tamoxifen- $\mathrm{N}$-oxide and its novel reduction back to tamoxifen by human cytochromes $\mathrm{P} 450$ and hemoglobin. Drug Metab Dispos 2005, 33(10):1446-1452.

37. Kallstrom AC, Salme R, Ryden L, Nordenskjold B, Jonsson PE, Stal O: 17ssHydroxysteroid dehydrogenase type 1 as predictor of tamoxifen response in premenopausal breast cancer. Eur J Cancer 2010, 46(5):892-900

38. Jansson A, Delander L, Gunnarsson C, Fornander T, Skoog L, Nordenskjold B, Stal O: Ratio of 17HSD1 to 17HSD2 protein expression predicts the outcome of tamoxifen treatment in postmenopausal breast cancer patients. Clin Cancer Res 2009, 15(10):3610-3616.

39. Justenhoven C, Hamann U, Pierl CB, Baisch C, Harth V, Rabstein S, Spickenheuer A, Pesch B, Bruning T, Winter S, Ko YD, Brauch H: CYP2C19*17 is associated with decreased breast cancer risk. Breast cancer research and treatment 2009, 115(2):391-396

40. Stearns V, Johnson MD, Rae JM, Morocho A, Novielli A, Bhargava P, Hayes DF, Desta Z, Flockhart DA: Active tamoxifen metabolite plasma concentrations after coadministration of tamoxifen and the selective serotonin reuptake inhibitor paroxetine. J Natl Cancer Inst 2003, 95(23):1758-1764.

41. Jordan VC: New insights into the metabolism of tamoxifen and its role in the treatment and prevention of breast cancer. Steroids 2007, 72(13):829-842

42. Meltzer NM, Stang P, Sternson LA, Wade AE: Influence of tamoxifen and its $\mathrm{N}$-desmethyl and 4-hydroxy metabolites on rat liver microsomal enzymes. Biochem Pharmacol 1984, 33(1):115-123.

43. Schmitt M, Klinga K, Schnarr B, Morfin R, Mayer D: Dehydroepiandrosterone stimulates proliferation and gene expression in MCF-7 cells after conversion to estradiol. Molecular and cellular endocrinology 2001, 173(1-2):1-13.

44. Lum SS, Woltering EA, Fletcher WS, Pommier RF: Changes in serum estrogen levels in women during tamoxifen therapy. Am J Surg 1997, 173(5):399-402.

45. Adlercreutz H, Martin F, Jarvenpaa P, Fotsis T: Steroid absorption and enterohepatic recycling. Contraception 1979, 20(3):201-223.

46. Kisanga ER, Mellgren G, Lien EA: Excretion of hydroxylated metabolites of tamoxifen in human bile and urine. Anticancer Res 2005, 25(6C):4487-4492.

47. Rock CL, Flatt SW, Laughlin GA, Gold EB, Thomson CA, Natarajan L, Jones LA, Caan BJ, Stefanick ML, Hajek RA, Al-Delaimy WK, Stanczyk FZ, Pierce JP: Reproductive Steroid Hormones and Recurrence-Free Survival in Women with a History of Breast Cancer. Cancer Epidemiol Biomarkers Prev 2008, 17(3):614-620.

48. Lönning PE, Johannessen DC, Lien EA, Ekse D, Fotsis T, Adlercreutz H: Influence of tamoxifen on sex hormones, gonadotrophins and sex hormone binding globulin in postmenopausal breast cancer patients. 
The Journal of steroid biochemistry and molecular biology 1995, 52(5):491-496.

49. Lien EA, Solheim E, Ueland PM: Distribution of tamoxifen and its metabolites in rat and human tissues during steady-state treatment. Cancer research 1991, 51(18):4837-4844.

50. Kisanga ER, Gjerde J, Guerrieri-Gonzaga A, Pigatto F, Pesci-Feltri A, Robertson C, Serrano D, Pelosi G, Decensi A, Lien EA: Tamoxifen and metabolite concentrations in serum and breast cancer tissue during three dose regimens in a randomized preoperative trial. Clin Cancer Res 2004, 10(7):2336-2343.

51. Jin Y, Desta Z, Stearns V, Ward B, Ho H, Lee KH, Skaar T, Storniolo AM, Li L, Araba A, Blanchard R, Nguyen A, Ullmer L, Hayden J, Lemler S, Weinshilboum RM, Rae JM, Hayes DF, Flockhart DA: CYP2D6 genotype, antidepressant use, and tamoxifen metabolism during adjuvant breast cancer treatment. J Natl Cancer Inst 2005, 97(1):30-39.

52. Kisanga ER, Gjerde J, Guerrieri-Gonzaga A, Pigatto F, Pesci-Feltri A, Robertson C, Serrano D, Pelosi G, Decensi A, Lien EA: Tamoxifen and metabolite concentrations in serum and breast cancer tissue during three dose regimens in a randomized preoperative trial. Clin Cancer Res 2004, 10(7):2336-2343.

Pre-publication history

The pre-publication history for this paper can be accessed here: http://www.biomedcentral.com/1471-2407/10/313/prepub

doi: 10.1186/1471-2407-10-313

Cite this article as: Gjerde et al., Associations between tamoxifen, estrogens, and FSH serum levels during steady state tamoxifen treatment of postmenopausal women with breast cancer BMC Cancer 2010, 10:313

Submit your next manuscript to BioMed Central and take full advantage of:

- Convenient online submission

- Thorough peer review

- No space constraints or color figure charges

- Immediate publication on acceptance

- Inclusion in PubMed, CAS, Scopus and Google Scholar

- Research which is freely available for redistribution

Submit your manuscript at www.biomedcentral.com/submit
Ciomed Central 